\title{
Alendronate increased bone mineral density but did not reduce new fractures in glucocorticoid induced osteoporosis
}

\author{
Saag KG, Emkey R, Schnitzer TF, et al, for the Glucocorticoid-Induced Osteoporosis Intervention Study Group. \\ Alendronate for the prevention and treatment of glucocorticoid-induced osteoporosis. $\mathrm{N} \mathrm{Englf} \mathrm{Med}$ \\ 1998;339:292-9.
}

\section{Question}

In patients who have osteoporosis that is induced by long term glucocorticoid treatment, is alendronate effective for increasing bone mineral density (BMD) and reducing new fractures?

\section{Design}

2 parallel randomised, placebo controlled trials with 48 weeks follow up.

\section{Setting}

15 centres in the US and 22 centres in other countries.

\section{Patients}

560 patients who were $17-83$ years of age and had rheumatological, pulmonary, dermatological, gastrointestinal, or other diseases that required $\geqslant 1$ year of glucocorticoid treatment (daily dose $\geqslant 7.5 \mathrm{mg}$ of prednisone or its equivalent). Exclusion criteria were evidence of metabolic bone disease (other than glucocorticoid induced or postmenopausal osteoporosis), low serum 25hydroxyvitamin D concentrations, concomitant drug treatments that might affect bone turnover, pregnancy, lactation, renal insufficiency, severe cardiac disease, or major upper gastrointestinal disease. A $2.5 \mathrm{mg}$ dose of alendronate was used in the multinational study only, and patients allocated to this group $(n=83)$ were not analysed. Patients ( $\mathrm{n}=477,30 \%$ men, $22 \%$ premenopausal women, $49 \%$ postmenopausal women) were stratified according to duration of glucocorticoid treatment: $<4$ months (34\%), 4-12 months $(21 \%)$, and $>12$ months $(45 \%)$.

\section{Intervention}

Patients were allocated to 1 of 3 treatments: alendronate, 5 $\mathrm{mg} /$ day $(\mathrm{n}=161)$ or $10 \mathrm{mg} /$ day $(\mathrm{n}=157)$, or a matching placebo $(n=159)$ for 48 weeks. Patients received elemental calcium, 800-1000 mg/day, and vitamin D, 250-500 IU/day.

\section{Main outcome measures}

Percentage change in BMD of the lumbar spine measured by dual energy $x$ ray absorptiometry. Secondary outcome measures included percentage changes in BMD of the trochanter, femoral neck, and total body; incidence of fractures; and adverse events.

\begin{abstract}
Main results
Analysis was by intention to treat. Compared with placebo, patients in the alendronate groups had greater percentage changes in $\mathrm{BMD}$ of the lumbar spine $(2.9 \% v-0.4 \%$, $\mathrm{p} \leqslant 0.001$ for $10 \mathrm{mg}$ alendronate and $2.1 \% v-0.4 \%$, $\mathrm{p} \leqslant 0.001$ for $5 \mathrm{mg}$ alendronate); femoral neck (1.0\% v $-1.2 \%, \mathrm{p}<0.001$ for $10 \mathrm{mg}$ alendronate and $1.2 \% v$ $-1.2 \%, \mathrm{p}<0.001$ for the $5 \mathrm{mg}$ alendronate); and trochanter $(2.7 \% v-0.7 \%, \mathrm{p} \leqslant 0.001$ for $10 \mathrm{mg}$ alendronate and $1.1 \%$ $v-0.7 \%, \mathrm{p} \leqslant 0.01$ for $5 \mathrm{mg}$ alendronate) at 48 weeks. BMD of the total body was analysed in $<80 \%$ of patients. The incidence of vertebral or non-vertebral fractures and overall or severe adverse events did not differ significantly between groups. Upper gastrointestinal adverse events occurred most frequently in the $10 \mathrm{mg}$ alendronate group ( $25 \%$ for $10 \mathrm{mg}$ alendronate, $19 \%$ for $5 \mathrm{mg}$ alendronate, and $16 \%$ for placebo, $\mathrm{p}$ for trend $<0.5$ ).
\end{abstract}

\section{Conclusion}

In patients with osteoporosis that is induced by long term glucocorticoid treatment, alendronate increased bone mineral density of the lumbar spine, femoral neck, and trochanter but did not significantly reduce the incidence of fractures.

Sources of funding: Merck \& Company and the General Clinical Research Centers Programs; National Center for Research Resources; National Institutes of Health.

For correspondence: $\operatorname{Dr} K \mathrm{~K}$ Saag, Clinical Immunology and Rheumatology, University of Alabama at Birmingham, 813-6 Amity South, MEB 625, Birmingham, AL 35294, USA. Fax +1 2059756859.

\section{Commentary}

Osteoporosis is a common complication of glucocorticoid therapy and causes significant morbidity. Nevertheless, it remains relatively neglected and many patients on long term glucocorticoid therapy receive no prophylaxis against bone loss. However, recent evidence from randomised controlled trials, including that by Saag et al, suggests that bisphosphonates are effective in the prevention and treatment of glucocorticoid induced osteoporosis. ${ }^{12}$ These agents, which inhibit bone resorption, are already widely used in the prevention and treatment of postmenopausal osteoporosis.

In the largest study by Saag et al the effects of alendronate were investigated in patients taking a median dose of around 10 $\mathrm{mg}$ of prednisolone daily at baseline. After 48 weeks, significant treatment benefits were demonstrated on bone mineral density (BMD) in the spine and proximal femur and, although the study was not powered to demonstrate a reduction in fracture, the overall incidence of vertebral fractures was lower in treated patients. These results are similar to those reported by Adachi and colleagues ${ }^{1}$ in a randomised controlled study of the effects of cyclical etidronate therapy. In this study, the baseline dose of prednisolone was rather higher (21-23 mg daily) and significant treatment benefits were observed in BMD in the spine and trochanter, but not the femoral neck or radius; fewer vertebral fractures occurred in the treatment group. 
In both studies patients were taking glucocorticoids for a variety of disorders and men and women over a wide age range were included.

These results are encouraging, although more data are required on anti-fracture efficacy at both vertebral and nonvertebral sites and it should be emphasised that the studies to date have been relatively short term. In view of its adverse gastrointestinal effects, ${ }^{3}$ alendronate should be used with particular caution in patients receiving glucocorticoids, and cyclical etidronate should be advised in those with a history of dyspepsia, reflux or other oesophageal disease. The most important message, however, is that effective prophylaxis against glucocorticoid induced bone loss can be achieved and should be used more widely by the many physicians who prescribe glucocorticoids for their patients.

J E COMPSTON Department of Medicine, Box 157, Level 5, Addenbrooke's Hospital,
Hills Road, Cambridge CB2 2QQ, UK

1 Adachi JD, Bensen WG, Brown J, et al. Intermittent etidronate therapy to prevent corticosteroid-induced osteoporosis. $N$ Engl f Med 1997;337:382-7.

2 Roux C, Oriente P, Laan R, et al. Randomised trial of effect of cyclical etidronate in the prevention of corticosteroid-induced bone loss. f Clin Endocrinol Metab 1998;83:1128-33.

3 de Groen PC, Lubbe DF, Hirsch LJ, et al. Esophagitis associated with the use of alendronate. N Engl F Med 1996;335:1016-21. 